\title{
Idiopathic recurrent pericarditis
}

INSERM

\section{Source}

INSERM. (1999). Orphanet: an online rare disease and orphan drug data base. Idiopathic recurrent pericarditis. ORPHA:251307

Idiopathic recurrent pericarditis is a rare autoinflammatory syndrome defined as recurrence of pericardial inflammation of unknown orig in following the first episode of acute pericarditis and a symptom-free interval of 4-6 weeks or longer. Recurrent attacks of chest pain may be the sole presentation or the chest pain may be accompanied by pericardial friction rub, electrocardiog raphic or echocardiographic changes, pericardial effusion and increased C-reactive protein. Cardiac tamponade is a rare, life-threatening complication. 